\title{
EVALUATION OF THE CLINICAL PROFILE OF PATIENTS WITH SPONDYLOARTHRITIS TREATED AT A TERTIARY SERVICE
}

\author{
Gabriel Sarkis Benacon ${ }^{1}$, Luciana Costa Pinto da Silva¹, Sandra Lúcia Euzébio Ribeiro ${ }^{1}$, Lucila Cristina Tomé Garcia ${ }^{1, \star}$, Cecília \\ Tizatto Barroso ${ }^{1}$, Gabriella Bacellar Marques ${ }^{1}$, Samuel Elias Basualto Dias ${ }^{1}$, Giovanna Dib de Almeida ${ }^{1}$, Gustavo de Albuquerque \\ Barros $^{1}$
}

1.Universidade Federal do Amazonas, Manaus (AM), Brazil.

*Corresponding author: lucilanaoluciola@gmail.com

\section{BACKGROUND}

Spondyloarthritis (SpA) is a group of inflammatory disorders that share clinical manifestations, genetic associations and pathogenic mechanisms, typically difficult to be diagnosed without evaluation by a rheumatologist. The SpA group includes ankylosing spondylitis (AS), psoriatic arthritis (PAs), reactive arthritis (ReA), enteropathic arthritis (EA) and undifferentiated spondyloarthritis (US). The difficulty in evaluating these diseases by nonrheumatologists and the lack of strategies for referring the suspected patient to the specialist result in a delay in the diagnosis of the disease and lead to subsequent investigations and unnecessary treatments, resulting in high costs and increased morbidity.

\section{METHODS}

Observational cross-sectional design based on the extraction and analysis of data from medical records of individuals affected by SpA, in the period from 2016 to 2020.

\section{RESULTS}

A total of 122 participants were included, $69.57 \%$ were male with a mean age of $46.76 \pm 13.05$ years; of which 78 participants had AS (63.93\%), 37 PAs (30.33\%), 4 EA (3.27\%), 1 US (0.81\%), 1 nonradiographic axial SpA (0.81\%) and 1 ReA (0.81\%), with a mean time from onset of joint symptoms to diagnosis of the disease of $5.88 \pm 8.36$ years and with a mean time from onset of extra-articular symptoms to diagnosis of $4.09 \pm 10.64$ years. The predominant clinical form was axial in 54 (44.26\%), peripheral in $31(25.41 \%)$ and mixed in 37 (30.27\%) of the participants. As for joint related clinical manifestations, there was the occurrence of: low back pain in 93 (76.23\%), pain in the buttocks in 29 (23.77\%), neck pain in 58 (47.54\%), thigh pain in $26(21.31 \%)$, lower limb arthritis in $73(59.83 \%)$, upper limb arthritis in 48 (39.34\%), enthesitis in 39 (31.97\%) and dactylitis in 19 (15.57\%) of the participants. As for extra-articular clinical manifestations, the following were present in the sample: anterior uveitis in 18 (14.75\%), inflammatory bowel disease in 8 (6.55\%), psoriasis in 37 (30.33\%) and urethritis in 7 (5.73\%) participants.

\section{CONCLUSION}

There is a great delay in the diagnosis of SpA in the state of Amazonas, following global trends. However, the sample studied demonstrates that there are differences in the prevalence of clinical manifestations of the disease compared to international groups, which should be taken into account in the evaluation of patients suspected of SpA and in the creation of screening and referral tools.

\section{KEYWORDS}

Spondyloarthritis, Referral, Clinical manifestations. 